\title{
Si-Passivated Ge Gate Sacks with Low Interface State and Oxide Trap Densities Using Thulium Silicate
}

To cite this article: Laura Zurauskaite et al 2020 ECS Trans. 98387

View the article online for updates and enhancements. 


\title{
Si-passivated Ge Gate Stacks with Low Interface State and Oxide Trap Densities Using Thulium Silicate
}

\author{
L. Žurauskaitè, A. Abedin, P.-E. Hellström, and M. Östling \\ Division of Electronics and Embedded Systems, KTH Royal Institute of Technology, \\ Kista 164 40, Sweden
}

\begin{abstract}
Ultra-thin epitaxially grown Si layers have been used for Ge surface passivation in CMOS devices utilizing standard silicon $\mathrm{SiO}_{2} / \mathrm{HfO}_{2}$ gate stack. In this work, we propose a high-k TmSiO interfacial layer, which has shown excellent performance on $\mathrm{Si}$, instead of the chemical $\mathrm{SiO}_{2}$. We successfully transfer a $\mathrm{TmSiO} / \mathrm{Tm}_{2} \mathrm{O}_{3} / \mathrm{HfO}_{2}$ gate stack from silicon to $\mathrm{Si}$-passivated $\mathrm{Ge}$ devices, yielding interface state density of $3 \cdot 10^{11} \mathrm{eV}^{-1} \mathrm{~cm}^{-2}$, which is comparable to $\mathrm{GeO}_{\mathrm{x}}$ passivation. Moreover, $\mathrm{Si}$-capped Ge gates with $\mathrm{TmSiO}$ interfacial layer achieve significant improvement in oxide trap density compared to $\mathrm{GeO}_{\mathrm{x}}$ passivation, exhibiting a potential for superior reliability. We further investigate the robustness of Si layer growth process and show that small $\left( \pm 3{ }^{\circ} \mathrm{C}\right)$ variations of growth temperature can be detrimental to the interface state density of the gate stacks.
\end{abstract}

\section{Introduction}

Germanium is considered as one of the options for future CMOS technology nodes due to its high intrinsic electron and hole mobilities. Ge surface passivation with a thin silicon layer (Si-cap) has been shown to be efficient for pFETs in terms of interface state density $\left(D_{i t}\right)$ and reliability because of a sufficient valence band offset between Ge and Si-cap, which confines the holes in the Ge layer. Strained Ge pFinFETs outperforming Si pFinFETs by four times higher mobility have been demonstrated using Si-cap process (1). Interfacial defects can be further passivated with a high-pressure anneal in $\mathrm{H}_{2}$ resulting in increased mobility in both pFETs (2) and nFETs (3). Moreover, negative (and positive) bias temperature instability reliability is improved when using Si-cap compared to $\mathrm{GeO}_{\mathrm{x}}$ passivation because of the energy decoupling between the holes (electrons) and traps in the gate oxide by introducing a dipole at $\mathrm{SiO}_{2} /$ high-k interface (2), (3). However, Si-cap process poses gate stack scalability issues because in order to achieve sufficient surface passivation, Si-cap thickness cannot be scaled. In fact, Si-cap thickness is one of the key parameters in achieving low interface state density $\mathrm{D}_{\mathrm{it}}$ (4), (5). An introduction of a high-k interfacial layer instead of a chemical oxide $\mathrm{SiO}_{2}$ could potentially help to scale down the equivalent oxide thickness. Integrating thulium silicate ( $\mathrm{TmSiO})$ as a replacement of $\mathrm{SiO}_{2}$ interfacial layer has been demonstrated on silicon (6), and a hole and electron mobility enhancement compared to $\mathrm{SiO}_{2} / \mathrm{HfO}_{2}$ gate stacks has been achieved for EOT $<1 \mathrm{~nm}(7)$. Moreover, we have previously shown the compatibility of $\mathrm{Tm}_{2} \mathrm{O}_{3}$ with

Ge by demonstrating $\mathrm{GeO}_{\mathrm{x}} / \mathrm{Tm}_{2} \mathrm{O}_{3}$ gate stacks with $\mathrm{D}_{\mathrm{it}}<5 \cdot 10^{11} \mathrm{eV}^{-1} \mathrm{~cm}^{-2}(8)$. In this work, we integrate $\mathrm{TmSiO}$ in $\mathrm{Si}$-cap process to achieve $\mathrm{D}_{\text {it }}$ comparable to $\mathrm{GeO}_{2}$ passivation while simultaneously achieving low oxide trap density. As Si-cap process conditions has 
been shown to impact the quality of resulting gate stack (9), we also investigate how small changes in Si-cap growth temperature affect the interface state density of the gate stack.

\section{Experiments}

Si-passivated Ge MOS capacitors were fabricated on virtual Ge substrates as schematically depicted in Figure 1 (a). Ge strain relaxed buffers (SRBs) were epitaxially grown on (100) oriented $100 \mathrm{~mm} \mathrm{Si}$ wafers by reduced pressure chemical vapor deposition (20 torr, ASM Epsilon 2000) in a two-step process using $\mathrm{GeH}_{4}$ precursor (10). Phosphine $\left(\mathrm{PH}_{3} 5 \%\right.$ in $\left.\mathrm{H}_{2}\right)$ was used as a dopant resulting in doping concentration of $1-3 \cdot 10^{16} \mathrm{~cm}^{-3}$. Si-caps were deposited in the same reactor at a nominal temperature of $400{ }^{\circ} \mathrm{C}$ using $\mathrm{Si}_{2} \mathrm{H}_{6}$. The growth temperature was also varied by $\pm 3{ }^{\circ} \mathrm{C}$ in order to test the robustness of the process conditions. Si growth was confirmed by testing that the surface of the wafer was hydrophobic, by spectroscopic ellipsometry and transmission electron microscopy (TEM). While trying to keep Si-cap exposure to air to a minimum, $400 \mathrm{~nm}$ $\mathrm{SiO}_{2}$ was deposited by plasma-enhanced chemical vapor deposition and active areas were defined.
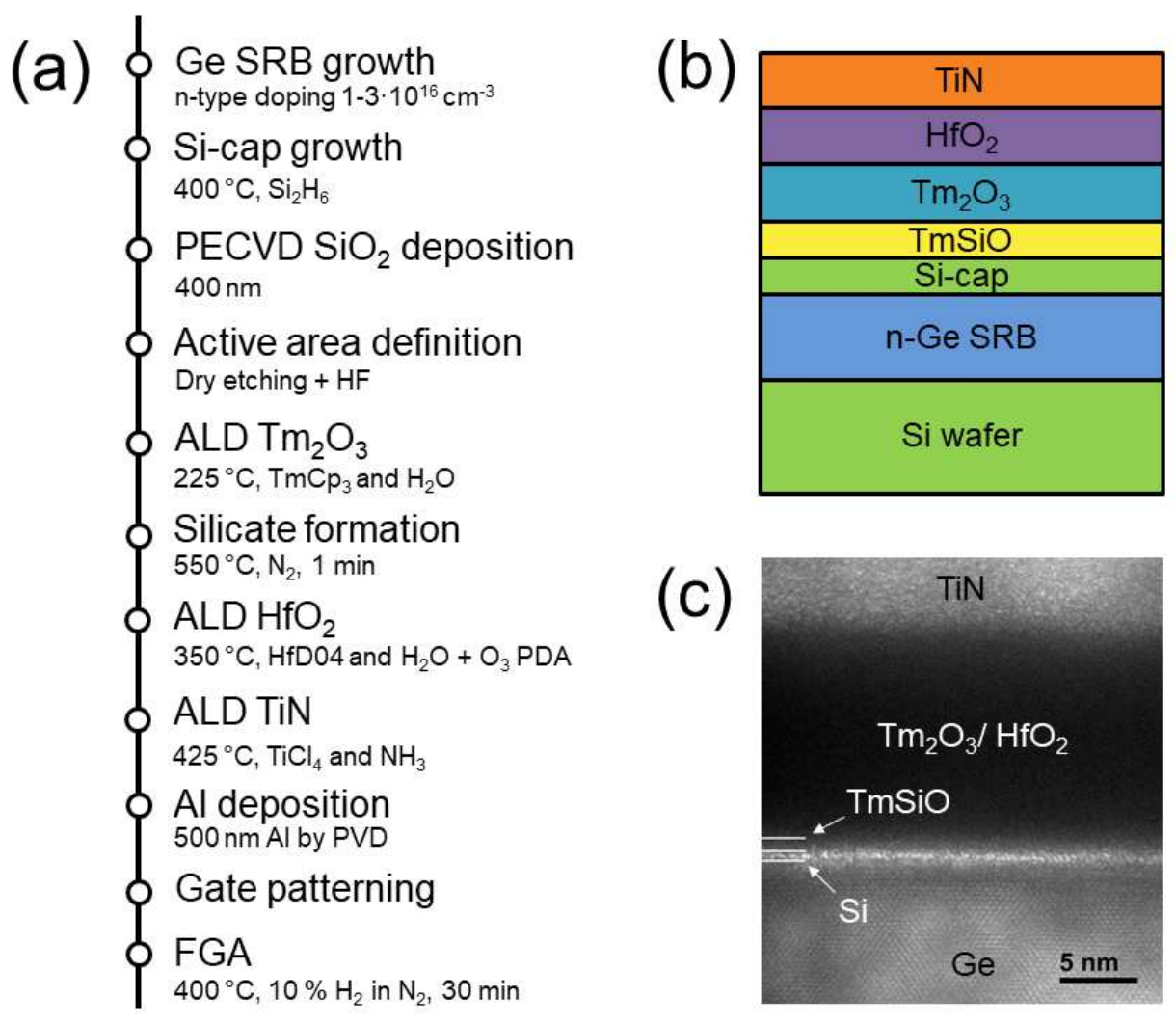

Figure 1. (a) Process flow of $\mathrm{Ge} / \mathrm{Si} / \mathrm{TmSiO} / \mathrm{Tm}_{2} \mathrm{O}_{3} / \mathrm{HfO}_{2} / \mathrm{TiN}$ MOS capacitor fabrication. $\mathrm{TmSiO}$ interfacial layer is formed by ALD growth of $\mathrm{Tm}_{2} \mathrm{O}_{3}$ followed by RTA at $550{ }^{\circ} \mathrm{C}$ in $\mathrm{N}_{2}$ for $60 \mathrm{~s}$. Interfacial layer formation is then followed by high-k $\mathrm{HfO}_{2}$ deposition and $\mathrm{O}_{3}$ PDA in ALD. ALD TiN is used as a gate metal. The resulting gate stack is schematically shown in (b) and cross-section TEM of the gate is shown in (c). 
Following the patterning of the active areas, the gate stacks were formed. The remaining $\mathrm{SiO}_{2}$ from the active areas was removed with $1 \% \mathrm{HF}$, and $\mathrm{Tm}_{2} \mathrm{O}_{3}$ was deposited by atomic layer deposition (ALD) at $225^{\circ} \mathrm{C}$ using $\mathrm{TmCp}_{3}$ and $\mathrm{H}_{2} \mathrm{O}$ precursors (11) with a target thickness of $7.4 \mathrm{~nm}$. Rapid thermal anneal (RTA) at $550{ }^{\circ} \mathrm{C}$ for $60 \mathrm{~s}$ in $\mathrm{N}_{2}$ was used for thulium silicate (TmSiO) interfacial layer formation. High-k $\mathrm{HfO}_{2}$ was deposited by ALD at $350{ }^{\circ} \mathrm{C}$ using HfD04 and $\mathrm{H}_{2} \mathrm{O}$ precursors (target thickness $5.6 \mathrm{~nm}$ ) followed by a post deposition anneal (PDA) in $\mathrm{O}_{3}$ for $10 \mathrm{~min}$. Gate stack was completed by $\mathrm{TiN}$ gate metal deposition at $425{ }^{\circ} \mathrm{C}$ by $\mathrm{ALD}\left(\mathrm{TiCl}_{4}\right.$ and $\mathrm{NH}_{3}$ precursors) and $500 \mathrm{~nm}$ $\mathrm{Al}$ was deposited by sputtering for electrical probing purposes. After patterning, forming gas anneal (FGA) of $10 \% \mathrm{H}_{2}$ in $\mathrm{N}_{2}$ at $400{ }^{\circ} \mathrm{C}$ for 30 min was performed. The resulting gate stack is schematically depicted in Figure 1 (b) and Figure 1 (c) shows a cross-section TEM of the gate stack indicating the layers. The TmSiO thickness is $\sim 1 \mathrm{~nm}$ leaving an unreacted Si layer of $\sim 0.5 \mathrm{~nm}$. Reference MOSCAPs with $\mathrm{Ge} / \mathrm{GeO}_{\mathrm{x}} / \mathrm{Tm}_{2} \mathrm{O}_{3} / \mathrm{HfO}_{2}$ gate stacks were also fabricated as described in (8) with addition of $\mathrm{ALD} \mathrm{HfO}_{2}$ and FGA.

Electrical characterization of MOS capacitors was performed with Cascade 12000 wafer prober and Keithley SCS 4200. Interface state density in the midgap was evaluated from capacitance-voltage $(\mathrm{CV})$ characteristics for 10 devices of each sample using a method described in (12).

\section{Results and Discussion}

\section{$\underline{\text { Si-passivated Ge gate stacks with TmSiO interfacial layer }}$}

Well behaved CV characteristics of a typical $\mathrm{Ge} / \mathrm{Si} / \mathrm{TmSiO} / \mathrm{Tm}_{2} \mathrm{O}_{3} / \mathrm{HfO}_{2} / \mathrm{TiN}$ MOS capacitor with Si-cap grown at a nominal temperature of $400{ }^{\circ} \mathrm{C}$ for $40 \mathrm{~min}$ are displayed in Figure 2 (a). Almost no frequency dispersion is observed. Interface state density and equivalent oxide thickness were extracted from $\mathrm{CV}$ characteristics of 10 MOSCAPs over a $100 \mathrm{~mm}$ wafer. $D_{\text {it }}$ was found to be $\sim 3 \cdot 10^{11} \mathrm{eV}^{-1} \mathrm{~cm}^{-2}$ and EOT of 3.75-3.8 $\mathrm{nm}$ as displayed in Figure 2 (b). Reference MOSCAPs with $\mathrm{Ge} / \mathrm{GeO}_{\mathrm{x}} / \mathrm{Tm}_{2} \mathrm{O}_{3} / \mathrm{HfO}_{2}$ gates exhibit a similar $D_{\text {it }}$ of $2 \cdot 10^{11} \mathrm{~cm}^{-2} \mathrm{eV}^{-1}$. The interface state density of Si-passivated Ge gates is also consistent with $\mathrm{TmSiO} / \mathrm{Tm}_{2} \mathrm{O}_{3}$ gate stacks previously shown on silicon, which yielded $\mathrm{D}_{\mathrm{it}} \sim 10^{11} \mathrm{eV}^{-1} \mathrm{~cm}^{-2}(6)$, demonstrating that no significant $\mathrm{D}_{\mathrm{it}}$ degradation occurs when transferring the gate stack process to Si-passivated germanium.

One of the challenges in Ge gate stacks is to simultaneously achieve high mobility and superior reliability. While low interface state density is a good indication of high mobility, low oxide trap density can show a potential for superior reliability. Oxide trap density $\mathrm{N}_{\mathrm{ox}}$ was extracted from the hysteresis of a dual CV sweep for both Si-cap and the reference $\mathrm{GeO}_{\mathrm{x}}$ MOS capacitors as displayed in Figure 3 as a function of the oxide electric field $\mathrm{E}_{\mathrm{ox}}$ and is defined as:

$$
E_{o x}=\frac{V_{G, \max }-V_{F B}}{C E T}
$$

Here $\mathrm{V}_{\mathrm{G} \text {,max }}$ is the highest voltage to which the dual sweep was performed, $\mathrm{V}_{\mathrm{FB}}$ is the flatband voltage and CET is capacitance equivalent thickness. The Si-passivated gates exhibit a hysteresis of only $\sim 3 \mathrm{mV}$ at $E_{\text {ox }}$ of $4 \mathrm{MV} / \mathrm{cm}$ corresponding to $\mathrm{N}_{\text {ox }}$ of $1.5 \cdot 10^{10} \mathrm{~cm}^{-2}$. It is more than 20 times lower than the oxide trap density of the reference 
$\mathrm{GeO}_{\mathrm{x}}$ devices, showing the superiority of Si-passivated gates. Low oxide trap density in $\mathrm{Ge} / \mathrm{Si} / \mathrm{TmSiO} / \mathrm{Tm}_{2} \mathrm{O}_{3} / \mathrm{HfO}_{2} / \mathrm{TiN}$ gate stacks indicates a potential for improved reliability.
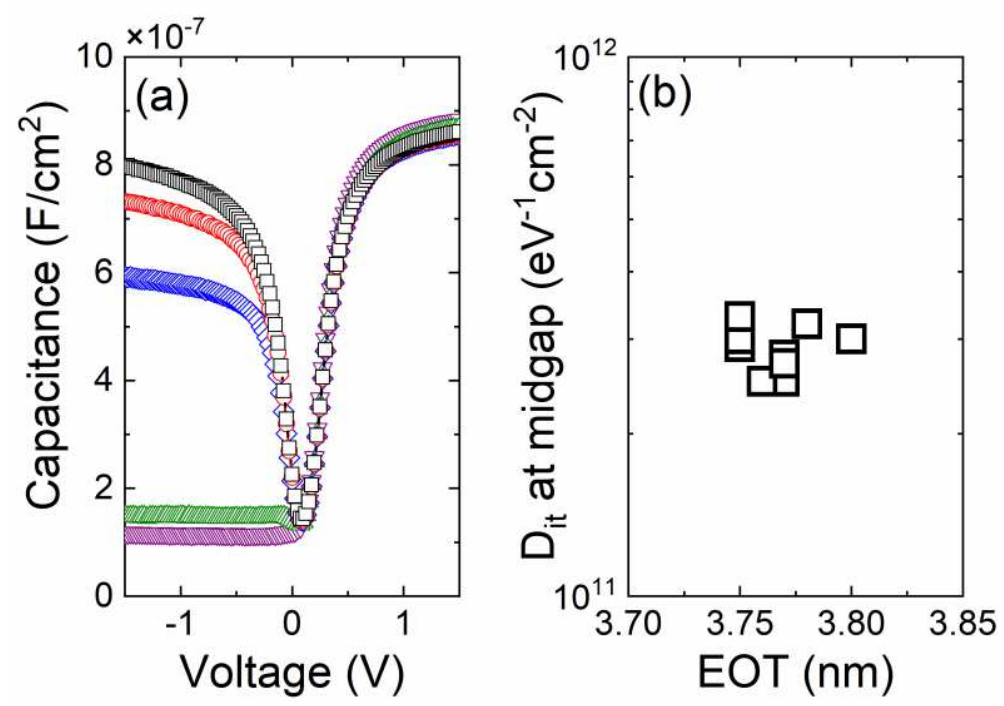

Figure 2. (a) $\mathrm{CV}$ characteristics of $\mathrm{Ge} / \mathrm{Si} / \mathrm{TmSiO} / \mathrm{Tm}_{2} \mathrm{O}_{3} / \mathrm{HfO}_{2} / \mathrm{TiN}$ gate stacks with $\mathrm{Si}$ cap growth at nominal temperature of $400{ }^{\circ} \mathrm{C}$ for $40 \mathrm{~min}$. (b) Interface state density is $2-4 \cdot 10^{11} \mathrm{eV}^{-1} \mathrm{~cm}^{-2}$ at EOT of 3.75-3.8 $\mathrm{nm}$.

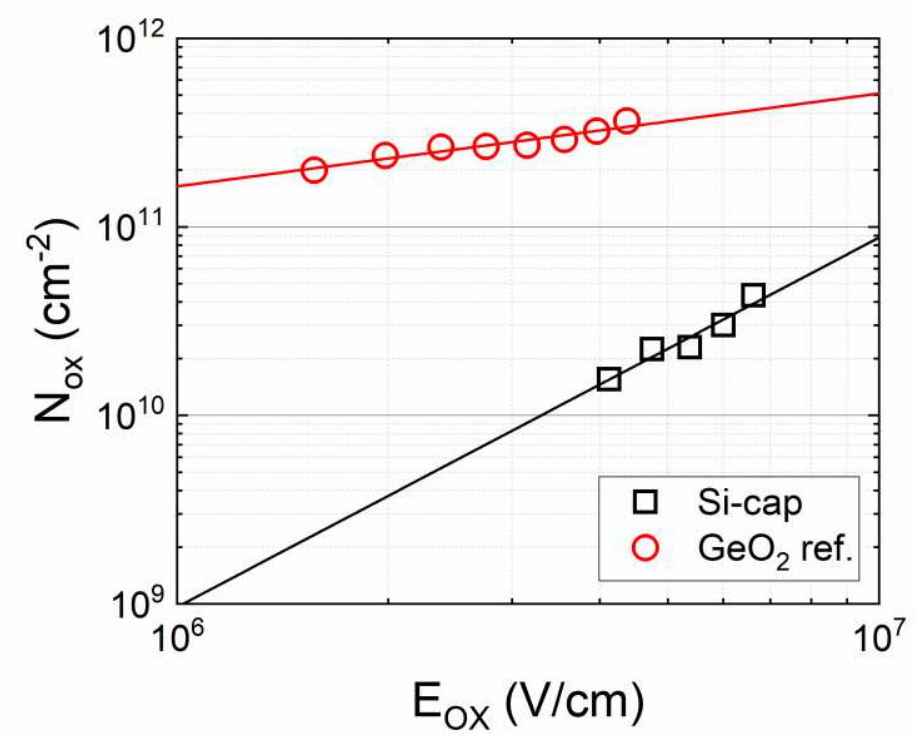

Figure 3. Oxide trap density $\mathrm{N}_{\mathrm{ox}}$ extracted from $\mathrm{CV}$ hysteresis as a function of oxide electric field $\mathrm{E}_{\mathrm{ox}}$. Si-cap devices exhibit more than 20 times lower oxide trap density than the reference $\mathrm{GeO}_{\mathrm{x}}$ devices.

\section{Influence of process parameters on interface state density}

Si layer thickness plays an important role in achieving low interface state density in Si-passivated gate stacks (4), (9). A Si thickness deviation of 1-2 monolayers can cause significant $D_{i t}$ degradation. As epitaxial growth rate is sensitive to temperature, small 
temperature deviations could potentially alter the Si layer thickness significantly, thus increasing the interface state density of the gate stack. The influence of Si-cap growth temperature on $\mathrm{D}_{\text {it }}$ was investigated by introducing a small (up to $\pm 3{ }^{\circ} \mathrm{C}$ ) deviation from the nominal growth temperature while keeping the growth time constant at $40 \mathrm{~min}$. The interface state density versus the deviation from the nominal temperature is displayed in Figure 4 where each point shows an average over 10 MOSCAPs and the error bars indicate one standard deviation. Even one degree deviation from the nominal temperature increases $\mathrm{D}_{\text {it }} 1.5-2$ times, from $3 \cdot 10^{11} \mathrm{eV}^{-1} \mathrm{~cm}^{-2}$ to $4.5 \cdot 10^{11} \mathrm{eV}^{-1} \mathrm{~cm}^{-2}$ and $6.5 \cdot 10^{11} \mathrm{eV}^{-1} \mathrm{~cm}^{-2}$ for $-1{ }^{\circ} \mathrm{C}$ and $1{ }^{\circ} \mathrm{C}$ deviation, respectively. If the growth temperature deviates from the nominal temperature more $\left( \pm 3{ }^{\circ} \mathrm{C}\right), \mathrm{D}_{\mathrm{it}}$ rises to above $10^{12} \mathrm{eV}^{-1} \mathrm{~cm}^{-2}$. The strong dependence of $\mathrm{D}_{\text {it }}$ on Si-cap growth temperature could be explained by the exponential growth rate dependence on temperature for $\mathrm{Si}$ growth temperatures $<650{ }^{\circ} \mathrm{C}(13)$. Small growth temperature differences could alter Si-cap thickness enough to significantly influence the interface state density which has been shown to be very sensitive to Si-cap thickness (4), (9). In addition, the variation of the interface state density within a wafer becomes larger as the growth temperature deviates from the nominal temperature more. At the nominal growth temperature, the standard deviation is less than $3 \cdot 10^{10} \mathrm{eV}^{-1} \mathrm{~cm}^{-2}$ while at $\pm 3{ }^{\circ} \mathrm{C}$ deviation from the nominal temperature, the standard deviation is more than $2 \cdot 10^{11} \mathrm{eV}^{-1} \mathrm{~cm}^{-2}$. Hence, temperature control when depositing Si-caps for $\mathrm{Ge}$ passivation is of a paramount importance for achieving low and uniform interface state density.

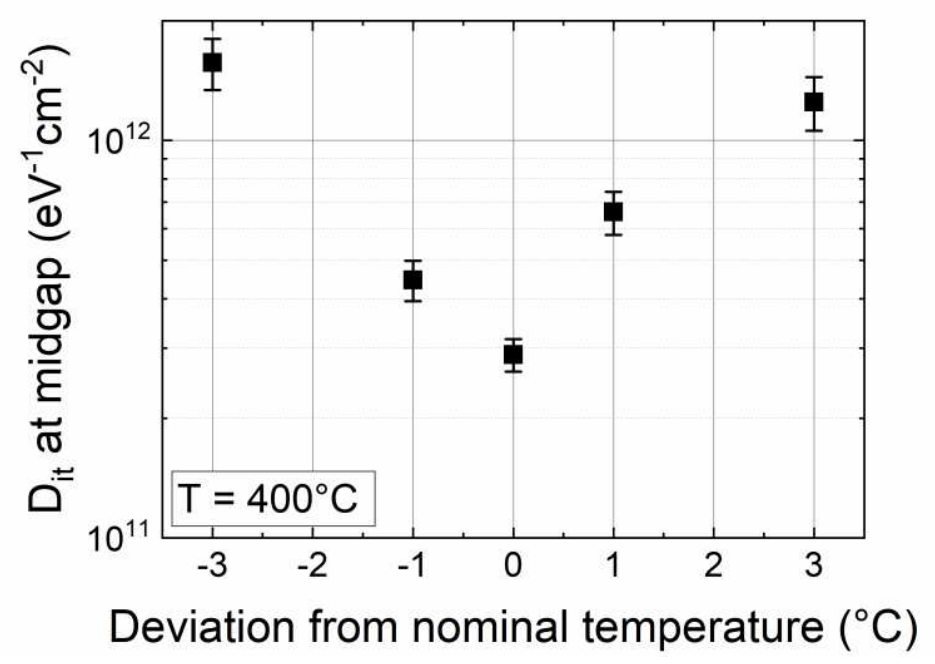

Figure 4. Interface state density in Si-passivated gate stacks versus deviation from nominal growth temperature. Growth time is set at $40 \mathrm{~min}$. Each point is an average over 10 measured MOS capacitors, and error bars indicate one standard deviation.

To further investigate the influence of the process parameters on the interface state density in Si-passivated gate stacks, Si-cap deposition time was varied. $D_{\text {it }}$ of $\mathrm{Ge} / \mathrm{Si} / \mathrm{TmSiO} / \mathrm{Tm}_{2} \mathrm{O}_{3} / \mathrm{HfO}_{2} / \mathrm{TiN}$ gate stacks with $\mathrm{Si}$-caps grown at three different temperatures (nominal $400{ }^{\circ} \mathrm{C} \pm 1{ }^{\circ} \mathrm{C}$ ) for $30-60 \mathrm{~min}$ is displayed in Figure 5 . The lowest $\mathrm{D}_{\mathrm{it}}$ for all growth temperatures is achieved at 40 min growth time and is $4.5 \cdot 10^{11} \mathrm{eV}^{-1} \mathrm{~cm}^{-2}$, $3 \cdot 10^{11} \mathrm{eV}^{-1} \mathrm{~cm}^{-2}$ and $6.5 \cdot 10^{11} \mathrm{eV}^{-1} \mathrm{~cm}^{-2}$ for $-1{ }^{\circ} \mathrm{C}, 0{ }^{\circ} \mathrm{C}$ and $1{ }^{\circ} \mathrm{C}$ deviation from nominal temperature, respectively. For shorter growth times interface state density increases 
rapidly, reaching more than $10^{12} \mathrm{eV}^{-1} \mathrm{~cm}^{-2}$ already at 35 min growth time for Si-caps grown $1{ }^{\circ} \mathrm{C}$ above the nominal temperature. A similar tendency is seen for longer growth times where $D_{\text {it }}$ is above $10^{12} \mathrm{eV}^{-1} \mathrm{~cm}^{-2}$ at 50 min growth time for all growth temperatures. Compared to other growth temperatures, the samples with Si-cap grown at $1{ }^{\circ} \mathrm{C}$ higher than nominal temperature exhibit degraded $\mathrm{D}_{\text {it }}$ for all growth times. On the other hand, interface state density of the samples with Si layer grown at the nominal temperature and 1 degree below becomes comparable for longer deposition times.

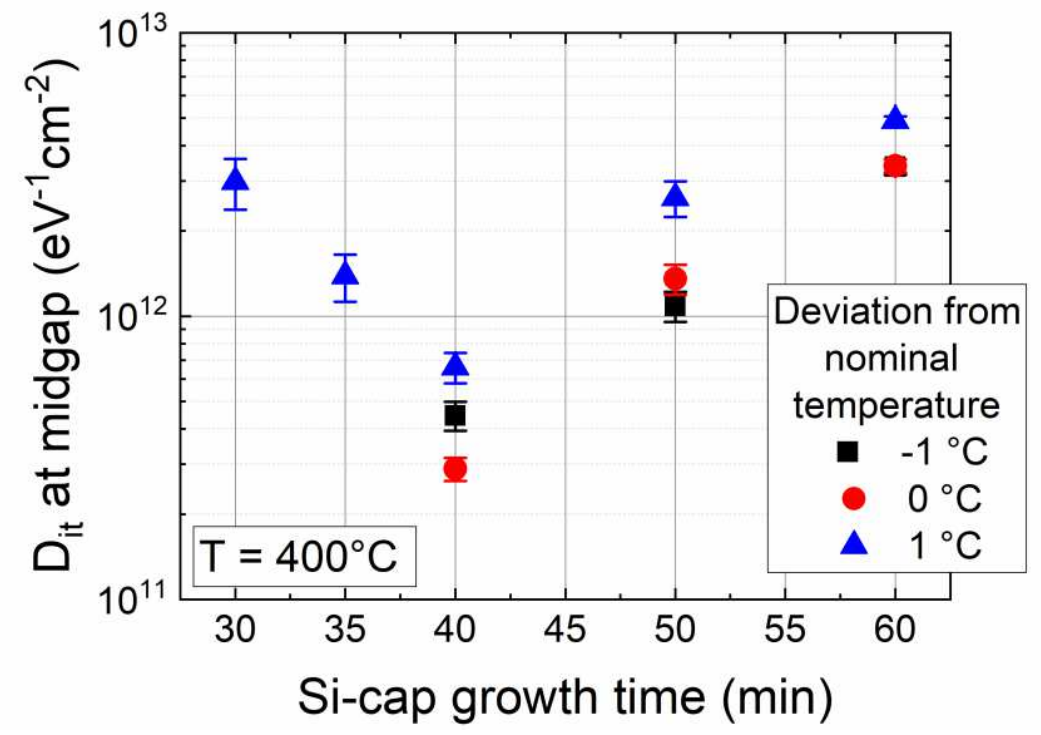

Figure 5. Interface state density of $\mathrm{Ge} / \mathrm{Si} / \mathrm{TmSiO} / \mathrm{Tm}_{2} \mathrm{O}_{3} / \mathrm{HfO}_{2} / \mathrm{TiN}$ gates as a function of the Si-cap growth time. The Si layer was grown at a nominal temperature of $400{ }^{\circ} \mathrm{C}$ and at two temperatures $\pm 1{ }^{\circ} \mathrm{C}$ from the nominal temperature. The average over 10 measured devices is displayed and the standard deviation is indicated with error bars.

\section{Conclusion}

A Si-cap process with high-k $\mathrm{TmSiO}$ interfacial layer has been demonstrated on $\mathrm{Ge}$ MOS devices yielding an average $D_{\text {it }} \sim 3 \cdot 10^{11} \mathrm{eV}^{-1} \mathrm{~cm}^{-2}$ over 10 devices with a standard deviation of $<3 \cdot 10^{10} \mathrm{eV}^{-1} \mathrm{~cm}^{-2}$. This result is similar to $\mathrm{GeO}_{\mathrm{x}} / \mathrm{Tm}_{2} \mathrm{O}_{3}$ passivation as well as with $\mathrm{Si}$ devices employing $\mathrm{TmSiO}$ interfacial layer. Si-capped Ge gates with a $\mathrm{TmSiO}$ interfacial layer also enable a significant improvement in oxide trap density compared to $\mathrm{GeO}_{\mathrm{x}}$ passivation, exhibiting a potential for superior reliability. Furthermore, a strong dependence of the interface state density on Si-cap growth temperature has been shown, when a substantial $\mathrm{D}_{\mathrm{it}}$ degradation was observed at only $\pm 3{ }^{\circ} \mathrm{C}$ deviation from the nominal growth temperature.

\section{Acknowledgments}

This work was supported by the Swedish Foundation for Strategic research. Fredrik Gustavsson is acknowledged for TEM images. 


\section{References}

1. J. Mitard, L. Witters, Y. Sasaki, H. Arimura, A. Schulze, R. Loo, L. A. Ragnarsson, A. Hikavyy, D. Cott, T. Chiarella, S. Kubicek, H. Mertens, R. Ritzenthaler, C. Vrancken, P. Favia, H. Bender, N. Horiguchi, K. Barla, D. Mocuta, A. Mocuta, N. Collaert, and A. V. Y. Thean, Dig. Tech. Pap. - Symp. VLSI Technol., 2016-Septe, 1-2 (2016).

2. H. Arimura, L. Witters, D. Cott, H. Dekkers, R. Loo, J. Mitard, L.-A. Ragnarsson, K. Wostyn, G. Boccardi, E. Chiu, A. Subirats, P. Favia, E. Vancoille, V. De Heyn, D. Mocuta, and N. Collaert, 2017 Symp. VLSI Technol., T196-T197 (2017).

3. H. Arimura, D. Cott, R. Loo, W. Vanherle, Q. Xie, F. Tang, X. Jiang, J. Franco, S. Sioncke, L.-A. Ragnarsson, E. Chiu, X. Lu, J. Geypen, H. Bender, J. W. Maes, M. Givens, A. Sibaja-Hernandez, K. Wostyn, G. Boccardi, J. Mitard, N. Collaert, and D. Mocuta, 2016 IEEE Int. Electron Devices Meet., 33.4.1-33.4.4 (2016).

4. K. Martens, J. Mitard, B. De Jaeger, M. Meuris, H. Maes, G. Groeseneken, F. Minucci, and F. Crupi, ESSDERC 2008 - 38th Eur. Solid-State Device Res. Conf., 138-141 (2008).

5. R. Loo, H. Arimura, D. Cott, L. Witters, G. Pourtois, A. Schulze, B. Douhard, W. Vanherle, G. Eneman, O. Richard, P. Favia, J. Mitard, D. Mocuta, R. Langer, and N. Collaert, ECS J. Solid State Sci. Technol., 7(2), P66-P72 (2018).

6. E. D. Litta, P. E. Hellstrom, C. Henkel, and M. Ostling, IEEE Trans. Electron Devices, 60(10), 3271-3276 (2013).

7. E. Dentoni Litta, P. E. Hellström, and M. Östling, Eur. Solid-State Device Res. Conf., 2, 155-158 (2013).

8. L. Žurauskaitè, L. Jones, V. R. Dhanak, I. Z. Mitrovic, P.-E. Hellström, and M. Östling, ECS Trans., 86(7), 67-73 (2018).

9. J. Mitard, K. Martens, B. DeJaeger, J. Franco, C. Shea, C. Plourde, F. E. Leys, R. Loo, G. Hellings, G. Eneman, W.-E. Wang, J. C. Lin, B. Kaczer, K. DeMeyer, T. Hoffmann, S. DeGendt, M. Caymax, M. Meuris, and M. M. Heyns, 2009 Proc. Eur. Solid State Device Res. Conf., 411-414 (2009).

10. A. Abedin, A. Asadollahi, K. Garidis, P.-E. Hellström, and M. Östling, ECS Trans., 75(8), 615-621 (2016).

11. E. D. Litta, P.-E. Hellstrom, C. Henkel, S. Valerio, A. Hallen, and M. Ostling, J. Electrochem. Soc., 160(11), D538-D542 (2013).

12. L. Zurauskaite, P.-E. Hellström, and M. Östling, 2017 IEEE Electron Devices Technol. Manuf. Conf. Proc. Tech. Pap., 164-166 (2017).

13. J. M. Hartmann, V. Benevent, J. F. Damlencourt, and T. Billon, Thin Solid Films, 520(8), 3185-3189 (2012). 